\title{
INVESTIGATION INTO CONTEMPLATING THE SELF IN A SPIRITUAL AND TRANSPERSONAL PSYCHOLOGICAL CONTEXT
}

\author{
S D Edwards, S Govender, D R \\ Nzima \& M M Hlongwane
}

\begin{abstract}
University of Zululand
Abstract

This article is intended as an original contribution towards contemplation of the Self with special reference to a spiritual and transpersonal psychological context. An integral approach involving a heuristic phenomenological investigation of four participant researchers' contemplation derived experiences is described. Individual and collective descriptions reveal immediate, direct, contact with the Self. This presence is indicated through universal, differential, unique, transpersonal, personal, spiritual, communal, applied psychological and relational descriptions. Findings support integral and other theoretical perspectives with special reference to ancestral consciousness and psychotherapeutic applications and implications of contemplation of the Self.
\end{abstract}

Keywords: Self, contemplation, phenomenology, spirituality, transpersonal, psychology

\section{INTRODUCTION}

As university psychology colleagues we were intrigued with questions as to what sourced existence, consciousness, strength, energy, creativity and our everyday working lives. We considered and discussed various concepts, terms, themes, phenomena, experiences, approaches and methodologies. For example, terms discussed included Source, Creator, God, Being and Spirit. We eventually decided that "the Self" was the most appropriate term for this mystical source yet present reality that reflected our spiritual, 
Investigation into contemplating the self in a spiritual and transpersonal psychological context.

transpersonal, psychological, multicultural, and community backgrounds and that contemplation of the Self was the most appropriate way to answer our questions. These research questions and our ensuing discussion lead to this exploratory, heuristic phenomenological investigation into contemplating the Self and its psychological applications from universal as well as local, spiritual, personal and applied psychological perspectives. The first author, who had previous experience in researching the Self, acted as lead investigator in co-coordinating and writing up the study, all aspects of which were consensually validated by all authors. A disclaimer is made that this writing intuitively recognizes the presence of the pre-existent Self and acknowledges that this and any other attempt to describe this reality is already a memory that will ultimately distort this presence. Paradoxically, it is this here and now ineffable Self who provides final motivation and direction for the writing.

\section{The Self}

Leahey (1987) has described the history of psychology in terms of humanity's attempt to understand the self. Various understandings also reveal various ways of conceptualizing the Self. These include spiritual, transpersonal, holistic, unitary, communal, relational, singular, differentiated, object relations, polycentric and integrated perspectives. To some extent these perspectives represent collective, human evolution and development from hypothesized origins in Africa over one hundred thousand years ago, followed by communal human migrations through Asia, Europe and the Americas (Jobling, Hurles \& Tyler-Smith, 2004), which were simultaneously reflected in distilled layers of the collective unconsciousness, as portrayed in the ensuing discussion. 
Myers (1993) has articulated fundamental philosophical assumptions of ancient African psychology. The main ontological assumption is that reality is at once spiritual and material, with an all-pervading spiritual energy as source and essence of all phenomena. Everything is spirit manifested where 'spirit' is known in extrasensory fashion via energy/consciousness/God through an extended Self -concept which includes ancestors, all of nature and the entire community. Spiritual healing logic embraces polarities yielding "both/and" conclusions, with axiology respectively emphasizing the value and interrelationships of communal, human, spiritual networks. Such understandings of Spirit and Self underlie the Zulu Umoya/Umphefumulo distinction, the Hindu Brahman/Atman distinction, Taoist heaven/earth and yang/yin polarities, Platonic ideas and archetypes. The words "know thyself" which were written on the walls of the temple at Delphi in early days, formed guiding instructions for early Greek and Roman civilizations, as well as sourcing the relatively recent views on consciousness (James), the unconscious (Freud), the collective unconscious (Jung), ego development (Loevinger) and Self psychology (Kohut). The following reflection from Jung (1961:196) is particularly relevant in the present context.

... "The goal of psychic development is the Self. There is no linear evolution: there is only a circumambulation of the Self. Uniform development exists, at most, only at the beginning; later everything points towards the centre. This insight gave me stability, and gradually my inner piece returned. I knew that in finding the mandala as an expression of the Self, I had attained what was for me the ultimate."

The views of Fonda (1995), Assagioli (2012) and Wilber (2000, 2007) provide composite respective updates of differentiated, synthetic and integrative perspectives on the 
Investigation into contemplating the self in a spiritual and transpersonal psychological context.

Self. Noting Western psychology views on the self as singular, unitary and developmental, Fonda (1995) has integrated psychoanalytic and postmodern, social constructionist perspectives in arguing for the notion of a polycentric self. He notes that the views of object relations theorists such as Klein, Winnicott and Fairbairn may all be adapted to reveal this differentiated understanding, not considered to be indicative of classical Western psychological thought. Nonetheless, it is an understanding of the self in a diverse world that contains diverse people with diverse interests. Fonda notes that recognition of a polycentric self requires more sensitivity, careful investigation, accurate observation and acceptance of the diversity inherent in the world, its individuals and their selves than has previously been the case.

Assagioli (2012:98) has distinguished ontogenetic, evolutionary and developmental meanings of the term "self" in the process of "self-identification". Firstly, individuals tend to view themselves in terms of important meanings, values and/or roles. This typically involves identifying with the ego and/or what gives the greatest sense of being. This may be her body for the beauty queen, or elite athlete, the emotional life for the lover, the mind for the intellectual, motherhood for the wife, breadwinner work for the husband etc. The second meaning is the inner experience of pure self-identity, awareness and/or consciousness, which typically does not arise spontaneously but only after inner experimentation and identification with the personal self. The third meaning of self-identification is that of realization of a higher, deeper and/or spiritual Self (which is written here with a capital letter to denote its transpersonal nature). Self-identification through progressive dis-identification with and/or transcendence of partial self-identifications is accelerated through meditation, where there is a progressive witnessing of bodily 
sensations, emotions, thoughts, the witness as witness, and beyond (Assagioli, 2012).

Wilber's (1996, 2000, 2007) non-dual approach integrates involving and evolving, or descending and ascending movements of consciousness present in every ecological, spiritual, psychological and physical breath inhalation and exhalation. In decent or inhalation, Spirit and Self involve into self-other, life-death, body-mind and ego-shadow dualisms. In ascent or exhalation, Spirit, consciousness and breath returns, evolves and develops towards ultimate nonduality, Self and Spirit. Mapping correlative basic structures in the stages of the self as conceptualized by over fifteen major self-theorists, Wilber (1996:95) documented as invariant pattern emerged in the form of development, from personal to transpersonal realms, which he describes as follows: "... at each point in evolution or remembrance, a mode of self becomes a component of a higher order self (e.g. the body was the mode of the self before the mind emerged, whereupon it becomes merely a component of self). This can be put in different ways, each of which tell us something important about development, evolution and transcendence: 1) what is whole becomes part; 2) what is identification becomes detachment; 3) what is context becomes content (that is, the context of cognition/experience of one level becomes simply a content of experience of the next; 4) what is ground becomes figure; 5) what is subjective becomes objective (until both of these terms become meaningless; 6) what is condition becomes element (e.g. the mind, which is the a priori condition of egoic experience, becomes merely a element in the higher order realms)..."

For Buddhism, one of Wilber's (2000) main inspirational sources, as well as other perennial philosophical and empirical traditions, all such terms as Self, no-self, Original Face, 
Investigation into contemplating the self in a spiritual and transpersonal psychological context.

no-face, permanent and impermanent, are equivalent, mere words for what is essentially unnamable, but apprehensible, recognizable through direct experience. In this context, Versveld (2010:54) writes of "the Self, which the ego obscures" and also of "The self, which excludes others, and the Self, which is found in the practice of the presence of God, and which is a return to what we are by nature, a gift of Ourselves to ourselves, occupy different times." Recognizing how, as human beings, we have arbitrarily cut up time, divided space, and alienated ourselves from Ourselves, we hope to convey some impression of both temporal, spatial selves and selfless Self in the following contemplations and applications.

\section{METHOD}

\section{Approach}

We chose Wilber's (2000) integral approach as we considered it to contain sufficient theoretical height, depth and breadth to frame our contemplation experiences. Wilber's $(2000,2007)$ approach is based on an integral philosophy of science, and a post-metaphysical, post-postmodern epistemology, that leads to an integral methodological pluralism (Wilber, 2007:33), which transcends and includes theoretical, paradigmatic perspectives such as positivism, interpretivism and social constructionism (Terre Blanche, Durrheim \& Painter 2006: 6). An integral, epistemological approach becomes possible if it is accepted that the same investigative sequence, the same three deep strands of science, run through all such perspectives. This investigative sequence consists of three phases: (a) an intuitive apprehension, (b) direct experience or resultant data discovery and (c) communal confirmation or rejection of the data. This also enables research investigations to integrate knowledge specific 
to various domains, such as matter, mind and spirit, as well as recognize logical category errors that occur if knowledge derived from one domain is confused with or substituted for knowledge from another domain. Contextualized within this theoretical, integral approach, the present study is heuristic and phenomenological in orientation, research methodology and practical investigation, with psychologists functioning as both researchers and participants, with special reference to their contemplation derived experience of the Self in a transpersonal psychological context (Moustakas, 1994). In other words, this approach required us to explore our contemplations from subjective and objective, individual and collective perspective.

\section{MODEL}

Wilber's $(2000,2007)$ AQAL model, which is shorthand for all quadrants, all levels, refers to a comprehensive system that integrates quadrants and levels, as well as lines, states and types of consciousness. The AQAL model postulates an essentially non-dual universe, with four quadrants, reflecting interior and exterior aspects of the individual and collective. The fundamental linkages in this universe are called holons, which are always both wholes and parts of other wholes, at various levels of consciousness experienced as matter, body, mind, soul and spirit, involving, evolving, moment to moment, in inter-being. In the present heuristic phenomenological study, as psychologists we contemplated the Self, with special reference to its spiritual and psychological applications and implications. Wilber's $(2000,2007)$ AQAL model enabled us to distinguish bodily, mental and spiritual levels of transpersonal, personal, interpersonal and impersonal dimensions of our Self contemplations. 
Investigation into contemplating the self in a spiritual and transpersonal psychological context.

\section{RESEARCH TECHNIQUE}

We chose contemplation as our research technique as it includes the reflective and reverential connotations of such terms as meditation and prayer in order to approach our subject matter of the Self and its psychological applications from an integral and holistic perspective. For us meditation typically constitutes reflection on interiority and prayer usually includes a divinity, whereas contemplation may be viewed as an advanced form of meditation and/or prayer that is experientially grounded as well as facilitative of insights and revelations. It has been described as "the highest expression of intellectual and spiritual life" (Merton 2000: 546),

\section{DESIGN}

An integrative, qualitative design was involved. The qualitative research methodology involved heuristic phenomenological analysis, synthesis, integration and discussion of contemplation derived experience from individual and collective descriptions, which were viewed from subjective, objective, collective and shared group perspectives.

\section{PARTICIPANTS}

As participants we knew each other for over twenty years, as Psychology students and staff. We thus constituted a volunteer, convenience sample, specifically self-selected for our established academic, interpersonal and community relationships, commitment to participate in the research, and willingness to explore, describe, explicate and articulate our experience. We defined ourselves as having suitable, qualitative characteristics for research purposes. We constituted 3 men and 1 women, with a mean age of 45 years and an age range from 38 to 62 years. Our interview language of communication was English. In terms of home language two 
of us spoke isizulu, one Tamil and one English. Although we were a very small, non-representative sample of researcher-participants, to some extent we represented the rainbow spectrum of consciousness of the population of South Africa. We all held doctoral degrees. In terms of professional work categories, we were 2 clinical psychologists, 1 educational psychologist and 1 counselling psychologist.

\section{ETHICAL MATTERS}

As participants we informed ourselves as to the nature of the research and provided individual and mutual consent with regard to the use of the information for publication purposes.

\section{PROCEDURE}

After appropriate establishment of rapport and discussion with regard to procedure, all contemplation sessions took place in a relaxed, comfortable and quiet setting. After individual contemplation session, participants typed descriptions of their experiences. These descriptions provided the basis for shared, inter-subjective, descriptions, discussions and interpretations of experiences. Research notes were kept throughout the process.

\section{Data Analysis:}

The qualitative research methodology involved heuristic phenomenological analysis of natural meaning units of experience, followed by synthesis into individual and collective summaries. The integrated qualitative, subjective and objective analysis and synthesis of the individual and collective data, as informed by Wilber's (2000), AQAL model, integral methodological pluralism (Wilber, 2007) and practical research knowledge (Terre Blanche, Durrheim \& Painter 2006) consisted of the following steps. Firstly, heuristic phe- 
Investigation into contemplating the self in a spiritual and transpersonal psychological context.

nomenological analysis included understanding, interpretation and consensual validation of our topic, approach, method of contemplation, data analysis, synthesis and integrative discussion. An essential aspect of all phenomenological analysis involved continuous, vigilant research attempts to remain open-minded so as to allow our individual and shared reality research participants to be accurately revealed. Secondly, there was holistic, repeated reading of all individual written protocols. Thirdly, individual profiles were analyzed into smallest naturally occurring units of experience (nmu's). Fourthly, each individual description was summarized. Fifthly, individual descriptions were integrated into a collective summary, based on the collation of the above mentioned phenomenological analysis. Sixth, individual and group data were integrated, analyzed, synthesized and discussed. Seventh, the completed research paper was circulated amongst us for critical reading and feedback, ethics, validity and integrity audit.

\section{RESULTS}

Qualitative findings follow in the form of phenomenological analysis of each participant's individual, descriptive, smallest, naturally occurring units of experience (nmu's). Each participant's description is preceded by a brief summary in bold type. Individual descriptions are followed by a more detailed, collective summary, with an audit trail of natural meaning units. The four participants are coded from $A$ to $D$ with regard to contemplation descriptions.

\section{Participant A}

As the reflected centre, which permeates all, the Self is a presence that can be felt but not seen. This Self presence is mediated through our ancestors, who are always with us wherever we go. The Self becomes the source of energy 
that guides everything we do and say in everyday life. Such presence enables a spontaneous, harmonious and continuous dialogue to flow in therapeutic relationships facilitating genuine and complete healing of clients.

Through meditation I was able to listen quietly to my body and feel myself (1). I could feel blood-energy flowing through my veins (2). My thoughts wondered about, through valleys and hills and eventually I felt I was connected with the Self (3), the reality and source of all energy (4). For me the Self is the centre of all being (5). It is the feeling of being in total full control of everything (i.e. internal locus of control) (6). It is a reflection of being (7) which is made possible by our ancestral spirits who are always with us wherever we go (8). The Self gives meaning and real sense for my existence and therefore of being in the world (9). Our ancestors play a significant role though in protecting and guiding us in all we do as human beings (10). Personally, when I survive accidents and recover from illnesses it is because of them (11). They show me their presence through dreams (12) and it is in this way that they make me feel and know their existence (13). They guide me through life so that when I do not behave I get punished (14). I am punished because the ultimate Being (UMvelinqgangi) does not subscribe to what I am doing at the time (15). Therefore ancestral spirits serve as mediators between the living and the ultimate Reality (uMvelinqgangi) (16).

The Self (Ongabonwayo), the one whose presence can be felt but not seen, permeates all being (17). Personally I feel in the centre of myself (ngizizwangiwumqemane), I can think and speak well (ngicabangefuthingikhulumekahle), listen attentively (ngilalelisise), and respond appropriately (ngiphendulengokufanelekile) because of the Self (18). The presence (ubukhona) of the Self in therapy (ukwelapha) 
Investigation into contemplating the self in a spiritual and transpersonal psychological context.

makes the intervention process effective (konkekuhambekahle) (19). As therapist (umelaphi) I feel His strong emotional presence (ukuxhumanangokomoya) which goes beyond the physical presence of both myself and the client (isiguli) in a therapeutic relationship (20). In life (empilweni) the Self is at a farther distance (uqhelile) from us (21), and hence our ancestors (amadlozi) play a mediatory role (bayasinxusela) between the living and the unseen (22). For instance I have to behave myself well (kumelengiziphathekahle) if I want the support of the Self through my ancestors in everything good which I desire to happen to me and my family (23). I have to show respect (inhlonipho) to the young and old (kwabancanenabadala) and treat them with human dignity (isithunzi) (24). When my clients are happy because of me, I also become happy and so the Self (25). In this way a strong sense of interconnectedness (ukuxhumana) and fulfillment (ukuneliseka) between the Self and my sense of being is achieved (26).

The presence of the Self is important in therapy and healing (27). It creates a sense of calmness and tranquillity which leads to an atmosphere conducive to inter-connectedness between the therapist and client (28). Once such an atmosphere is created it enables the dialogue to flow spontaneously in a therapeutic relationship (29). The Self makes me feel in the centre of myself (30), in full control of everything (31), and being able to think and talk properly and clearly for the benefit of the client (32). Thus the Self becomes the source of energy that guides everything I do and say in everyday of my living (33). It is the source of direction which enables my practice to give meaning to those who are in the receiving end (clients) (34). There must be a harmonious and continuous relationship between myself and the Self (35). This continuum gives a sense of direction and purpose 
for existence (36). Without the Self the therapeutic relationship can be doomed due to lack of intentionality and interconnectedness between the major role players (37). Hence the presence of the Self in a therapeutic relationship makes the client come out of therapy feeling a complete whole (38). A genuine and complete wholeness has been achieved, with all the loose parts put together (39).

\section{Participant B}

The Self is clearly recognized as an intimate personal presence, with whose energetic gendered qualities $A$ is in daily contact in a process that is helpful and healing. This Self presence permeates the therapeutic relationship, facilitating mutual understanding, respect, self inquiry and expression. It provides an atmosphere of calm, peace serenity, tranquillity, support, strength and healing to clients and their extended support system

It was a very quick twenty minutes (1). As always, for me, when contemplating on The Self time passes very quickly (2). Focus on The Self was a rejuvenating experience (3). It allowed me to free the mind (4) and relax in an otherwise busy day (5). It allowed me to connect with a greater sense of being and feeling (6). A heightened sense of relief (7) but at the same time (and I do know that this may sound contradictory), some anxiety because I always carry a certain sense of fear (8). I do not allow myself the luxury of completely surrendering to the process (9). My desire to control self does not allow me to truly focus on The Self (10). But I make time in my schedule no matter how busy I am and no matter where I am to focus on The Self (11). It is an important part of my daily routine (12) because the process is helpful and healing (13). The freedom, the natural abandon or the spontaneous floating on a breeze is often stopped 
Investigation into contemplating the self in a spiritual and transpersonal psychological context.

short just as I approach the edge of the cliff (14), it's a long drop (15) and I know the landing is soft (16) but the problem is I don't know what's at the bottom...(17).

My interpretation of The Self from an Hindu (South Indian, Tamil speaking family) is as a South African living in South Africa for 150 years (18) .We have for many years been taught about the Triad: Braham, Vishnu and Shiva - Creator, Preserver and Destroyer but my viewpoint would be that of life energy as depicted by Shiva (19). For me, Shiva has been my vessel of meditation and contemplation (20). This could be from both a physical (biological) and spiritual (emotional, psychological) perspective (21) and Shiva, the male manifestation, is viewed as the destroyer, he is seen as all powerful, can be the very core of our being (22) and his female counterpart or consort, Shakthi can be just as strong and powerful (23). They represent the fragility of life (24) and the element of unpredictability (25) and while we are all born with this uncertainty (26), we are reminded to not lose sight of this important aspect in our lives (27). This energy can often get "channelled away" or be "blocked" and can have detrimental effects, either physical or psychological in nature (28). We forget to stay focused and our life giving force will have to be reengaged or energized (29). Shiva/Shakthi is a strong element, powerful in that they have the ability to "get rid of" all negative elements and refocus one (30).

I believe contemplating on The Self teaches us much about listening to self and others (31) and this is one of the core principles of psychology (32). If as a psychologist you are comfortable with your sense of The Self then the client will very likely sense this, as it tends to permeate into all that you do (33). The Self is important in my experiences of healing (34). The client becomes more comfortable in my presence with their sense of The Self and feels freer to express 
their sense of The Self (35). There is a mutual understanding of and respect for The Self, sometimes even without even having spoken a word about The Self (36). It may then allow the client to feel free to delve into the ongoing process of The Self inquiry, should they feel the need (37) and this could lend considerable support to the client and their extended support system (38). Also contemplation of The Self creates an atmosphere of calm, peace, serenity and tranquility (39) and clients can read this energy in the environment and the people within that surrounding (40). Apart from the strength it provides one (41) it also allows one the gentleness to create an environment conducive to mental health healing (42).

\section{Participant C}

The Self exits in an undivided, warm and integrated relationship to God, ancestors, family and all other spiritual human, work and ecological relationships. Life and health are inextricably interrelated as a person without a healthy self is like a person without a soul and a person without a soul ceases to live. The self is the key to human existence and the Self as the beginning and end of life.

I, me and myself, get strength from God the Omnipotence and Almighty (1). I am built in the image of God (2) and I have Him in me and me in Him (3). The trinity lives in me and I am a part of the-three-in-one (4). God is my source like no other; I am because He is (5). I am connected to the universe and everything because of $\mathrm{Him}$ (6). I exist in me to serve Him and He strengthens and guides me to serve (7). I am the servant of God and of His people (8). Even though I sometimes I have no answers at the physical level, He is my spiritual answer (11). I am because $\mathrm{He}$ is, and He is everywhere as $\mathrm{He}$ is who $\mathrm{He}$ is (12). On earth I was introduced to 
Investigation into contemplating the self in a spiritual and transpersonal psychological context.

the world by my parents who taught me to be everything I am today (13). My family is my second source of strength (14). It is their love, concern, communication, understanding and support that makes the difference (15). Initially I existed in my parents, whose spirit I still breathe (16). They lived for me to be a better person (17). Their wishes are my drive, inspiration I carry over (18). Though they have gone to the other world, they live in me (19). I now exist with and in my wife who is the pillar of my strength and so should be life (20). I live in my children who bring so much joy in me, and to most of us in, (and many others) outside of the family (21). I live in my surroundings (22). I am my home and I am my work (23). I live better and work better when I am at peace with myself, my environment, my family and my colleagues (24). Peace reverberates peace, stability and more hard work (25). Disruption in one area directly affects the soul and self, and could have a negative effect on other areas (26). The self has a core around which the self-esteem and self-concept are born, nurtured and sustained (27). I live in my home, I live at my work and I am able to live everywhere and adjust to my work and world (28).

Application consists of making use of the self to harmonize experiences. The self is uplifting and self-supporting (29). It has the capability of transcending all spheres of life and experience (30). With a well-integrated self, one is able to overcome obstacles at work and at home and in personal life (31). A healthy self is able to deal successfully with the challenges of life (32). A healthy self is able to support and help others (33). A healthy self is neither selfish, nor proud (34). It is self-generating to give support to others in need (35). The self is key to human life and existence (36). A person without a healthy self is like a person without a soul (37), and a person without a soul ceases to live (38). Thank 
you God for the self and soul, many people are thus able to live satisfying lives (39). The self is the beginning and the end of life (40). God is Eternity of life, soul and the Self (41). In God we Trust (42).

\section{Participant D}

The Self is described from mystical, universal, spiritual and transpersonal psychological perspectives. Conscious breathing is used for contemplating the Self as well as healing, typically in workshops, which focus on public health, sport psychology, physical, mental and spiritual interventions. Such breath based contemplation includes explorations and transformations of consciousness and facilitation of all forms of applied psychology and healing in general.

As first author and principal investigator, for purposes of reflexivity, it needs stating that I am a South African with European and all other forms of ancestry(1), whose perspectives on the Self are contained in every word of this article (2). Having lived, studied and applied psychology with other South Africans of African, Asian, European and other ancestry, with special focus on indigenous knowledge systems, my personal perspectives on the Self consist of an integration of all these perspectives (3). As it would be too extensive and repetitive to describe such experiences in depth (4), I choose rather to disclose a particular bias towards breath consciousness forms of contemplation, prayer and or meditation in order to arrive at that universal consciousness that I call God, Godhead, Spirit, Absolute, Self, Emptiness, Presence, Silence, Ultimate Mystery, etc (5), which has different names in different spiritual and religious traditions such as uMvelinqgangi Nkulunkulu, Tixo, Mmopi, Umoya, Ruach, Brahmin, Tao, Christian Trinity of God the Father, Son and Holy Spirit, Allah etc (6). So I quite consciously use 
Investigation into contemplating the self in a spiritual and transpersonal psychological context.

breath/Spirit for this and many other reasons, such as healing of self and others (7). Through such contemplation, the little self transcends into a greater Self and Beyond, Singular and Plural, One and Many, Immanent, Transcendent, Relational, Communal, Trinity, Love, Peace, Unity Consciousness, all of which terms describe a Presence that is mystical and ineffable, but at the same time right here and now (8).

In concrete phenomenological terms, breath is experienced as energy arising out of consciousness (9). While I do use breath in personal counselling sessions (10), for healing of self and others (11), my main focus has been on offering workshops for various groups such as student counsellors, academic staff, mental health professionals, sportspeople as and members of the general public (12). In addition to academic writings, I view breath psychology and psychotherapy as probably the most valuable public health intervention I can offer (13). Some articles appear in the reference section (14). In addition to Christian, African, Asian and other spiritual healing traditions (15), authors such as Harriet Ngubane, Credo Mutwa, Ken Wilber, Daniel Reid, Trish Sherwood and Roberto Assagioli have also provided inspirational sources (16).

This is the essential way the healing (whole making) works the process involved (17). Through universal and ancestral consciousness, the Self drives the breath through spirit to soul to mind to body to matter (18). Intent, will, belief, practice (19) as well as all other universal characteristics of healing, such as therapeutic relationship, love, care, dialogue and the rest are also all essential (20). Research shows that particular types of conscious breathing exercises are associated with psycho-neuro-immunological benefits (21) as well as generally alkalizing and oxygenating the body (22). For example, in a very practical way, slow, heartbeat syn- 
chronized breathing at about 6 breaths per minute facilitates harmonious Self contemplation (23). Every in-breath may be experienced as bringing in pure unity consciousness/Spirit/Umoya/Emptiness/Brahmin/Godhead (at causal level) (24) through to belongingness and love healing (at subtle level) (25) to improved blood circulation as it synchronizes with heart and other structural/functional units through to increased ventilation of lungs, muscles around lungs/ribs, through to skin (at gross physical level) (26) and into environment again with every out-breath (27). Such contemplative revelations continually calm body, mind and spirit, (28), facilitate re-connection with our greater Self (29), and effect healing in all senses, bio-psycho-social as well as moral, spiritual, ecological etc (30).

\section{COLLECTIVE SUMMARY}

Universal, differential and unique aspects of the Self are described. Universal spiritual, transpersonal aspects especially emphasize the immanent (A17, B36, C41, D8) and transcendent (A33, B6, C30, D8) qualities of the Self. Although all participants emphasize both universal (A17, B31, C41, D8) and differential (A8, B8, C22, D3) aspects of the Self, differential aspects become especially apparent with regard to indigenous and/or local perspectives. For example, although all participants describe the Self in absolute terms, for example as ultimate Being/Reality (A15), Creator, Preserver and Destroyer (B19), God (C41) and/or Godhead (D5), A places relatively greater emphasis on ancestral consciousness (A16), B on the energetic nature of Shiva/Shakhti, $C$ on harmonious spiritual, familial, and community relationships, and $D$ on contemplation and healing. In addition to universal and differential emphases, all participants' descriptions also contain unique perspectives on the Self which deserve particular mention. For A, the Self is Ongabonwayo, one whose 
Investigation into contemplating the self in a spiritual and transpersonal psychological context.

presence can be felt but not seen (A17); for B, the Self is awesome and rejuvenating (A3-17); for C, God is Eternity of life, soul and the Self (C41) and, for D, breath consciousness exercises are key to facilitate re-connection with our greater Self (D29).

As we had intended and discussed, all descriptions portray the Self from spiritual, transpersonal (A5, B6, C41, D5), personal (A6, B2, C1, D1), indigenous (A17, B19, C19, D6) and applied psychological (A27-39, B31-42, C29-42, D 9-30) perspectives. The Self is described as being present in matter (A2-3, B14, C22, D9), body (A1,B8, C16, D22), mind (A9, B4, C27, D18), soul (A24, B22, C19, D18) and spirit (D8, $B 21, C 11, D 6)$. Relational qualities of the Self become particularly apparent when participants describe the presence and function of the Self in applied psychological, therapeutic and healing contexts. A great many qualities of the Self are described. These include a source of energy that guides everything that is said and done, the enabling of spontaneous, harmonious dialogue A27-39), facilitating mutual understanding, respect, self inquiry and expression (B31-42), that is self-generating, supportive and helpful (C 29-33). Through universal and ancestral consciousness, the Self drives the breath through spirit to soul to mind to body to matter. Intent, will, belief, practice as well as all other universal characteristics of healing, such as therapeutic relationship, love, care, dialogue and the rest are also all essential (D18-20). 


\section{DISCUSSION}

Our individual and collective descriptions reveal immediate, direct, contact with the Self. This presence is indicated through universal, differential, unique, transpersonal, personal, spiritual, communal, applied psychological and relational descriptions. We consciously focussed on local African and Indian aspects. Descriptions supported previous findings that Wilber's (2000) integral approach is complemented and extended through ancestral consciousness and its associated beliefs and practices, which precede and ground contemporary human existence, consciousness and all related spiritual and religious traditions and systems (Edwards, Thwala, Mbele, Siyaya, Ndlazi \& Magwaza, 2011). The essence of this dimension is awareness of the authentic, living, immanent and transcendent, spiritual and physical presence of senior kinsmen, living and dead, extending in an unbroken line back to Self, God and/or Spirit. The descriptions support both Wilber $(2000,2007)$ and Assagioli's (2012) models, which are based on the perennial philosophy that involution precedes evolution, or that spirit is already involved in matter, and that ontogeny replicates phylogeny, that is, individual human development replicates evolutionary unfolding. We describe psychological and spiritual development as essentially concerned with the evolution and transcendence of consciousness through body to mind to self to Self, Soul and/or Spirit.

According to Visser (2003), transpersonal development truly begins when the centre of the Self begins to inhabit the realms of the Soul. Our local African and Indian descriptions indicate that ancestral consciousness forms a vital, mediating, communal spiritual bridge in this development. Wilber (1982) initially distinguished two sub-realms of transpersonal consciousness, based on meditative traditions, where the 
Investigation into contemplating the self in a spiritual and transpersonal psychological context.

Self, also referred to as the Witness in Vedanta, firstly observes experiences, feelings and thoughts with more detached clarity, before disappearing as a separate entity in identification with the Absolute. In Zen, this witnessing Self is recognized as the subtlest of all illusions that dissolves in Emptiness/Sunyata. In Wilber's (1982:66) words: "In the lesser state, one's deepest self intuits Godhead; in the ultimate state one's deepest self gives way to Godhead, and that is the Supreme Identity (bhava samadhi, sahaja samadhi, and so on)". Assagioli (2012) refers to this mystical realm as the Supreme Synthesis. For most humans, this ultimate reality will probably forever remain a realizable state rather than stage of constant consciousness. However contemplation of any such reality typically accelerates further commitment to human development, health, welfare and creative evolution as is evident in the participants applied psychological descriptions.

Perennial psychological and spiritual traditions are in accord as to the fundamental interconnectedness of the universe with every thing involved in everything else. Steiner's (1999) tripartite model, informed by esoteric philosophy, mystical Christianity and Hinduism, provides an interesting contrast to Wilber's (2000, 2007) and Assagioli's (2012) models. Similar to Wilber's $(2000,2007)$ distinction between first and second tier thinking, Steiner (1999) introduces the notion of thresholds distinguishing levels of body, soul and spirit, with a first threshold distinguishing body and soul and a second threshold distinguishing soul and spirit. Sherwood (2012) has adapted Steiner's (1999) scheme to distinguish personal and spiritual levels, which she refers to as "I am" and "I AM" respectively. Thus body, soul and spirit are further differentiated into three levels each, making nine levels in all: respectively termed physical, etheric and sentient body; sen- 
tient soul (I am), intellectual soul (I am), and consciousness soul (I am); and Spirit Self (I AM), Life Spirit (I AM) and Spirit Human (I AM). Similar to Assagioli and Wilber's schemes the first and second threshold may be viewed as distinguishing personal and spiritual psychosynthesis or personal and transpersonal consciousness development respectively.

In referring to self-transcendent realms, meditative and/or contemplative traditions recognize that some sense of self must have first developed in order for it to be transcended (Wilber, Engler \& Brown, 1986). Thus we have the soul-spirit (umphefumulo/uMoya) distinction in Zulu traditions, the Atman-Brahman distinction in Hinduism, the self-not self distinction in Buddhism. With varying degrees of direct experiential, definitional clarity, African, Judaic, Hindu, Taoist, Buddhist and Islamic contemplative traditions also typically delineate states and stages of consciousness transformations. For example, Eastern Orthodox Christian traditions refer to contemplative states and unfolding stages of image, metanoia, apathea, illumination and theosis (Chirban, 1985; Wilber, 2000). From an integral, psychological and spiritual perspective this implies continuous transformation beyond self-identification, self actualization and Self realization. Such transpersonal, spiritual dimensions are conveyed by the famous Zen master, Dogen: "To study the self is to forget the self, to forget the self is to be one with others (Epstein, 1996:20). Similarly Christ affirmed "before Abraham was I AM." In practice this infers the Buddhist Bodhisattva vow and/or Christian commitment of loving God and neighbour.

A special contribution of the present study is the applied psychological implications of Self contemplation. The therapeutic context becomes characterized by authentic, caring, human, interpersonal and communal spiritually, in a word, 
Investigation into contemplating the self in a spiritual and transpersonal psychological context.

ubuntu (Edwards et al. 2004). Participants describe how the presence of the Self in therapeutic relationships facilitates transformation, integration and healing. It is described as a source of energy that guides everything that is said and done, facilitating spontaneous, harmonious dialogue, mutual understanding, respect, self inquiry, self expression that is self-generating, supportive and helpful as well as other universal characteristics of healing. In this context, Assagioli (2012:189) writes: 'Our spiritual being, the Self, which is the essential and most real part of ourselves, is concealed, confined and "enveloped" first by the physical body with its sense impressions, then by the multiplicity of the emotions, and the different drives (fears, desires, attractions and repulsions) and finally by the restless activity of the mind. The liberation of the consciousness from the entanglements is an indispensable prelude to the revelation of the spiritual Centre." Our descriptions thus strongly support research that indicates that regular contemplation facilitates helping others live within this Self, It is in this spirit that we offer this writing.

\section{BIBLIOGRAPHY}

Assagioli, R. 2012. Psychosynthesis. A collection of basic writings. Amherst, MA; The Synthesis Centre.

Chirban, J. 1986. Development stages in Eastern Orthodox Christianity. In Wilber, K., Engler,, J. \& Brown, D.P. (Eds.) Transformations of consciousness: conventional and contemplative perspectives on development (pages 285-314) Boston, M.A: Shambhala.

Edwards, S.D. 2012. Effect of African breath psychotherapeutic workshops on spirituality perceptions and experiences. Indilinga. African Journal of Indigenous Knowledge Systems, 11(2), 49-60.

Edwards, S.D., Makunga, N.V., Ngcobo, H.S.B. \& Dhlomo, R.M. 2004. Ubuntu: a fundamental method of mental health promotion. International Journal of Mental Health Promotion, 6(4), 16-21. 
Edwards, S.D., Thwala, J.D., Mbele P.B., Siyaya, V, Ndlazi, N. \& Magwaza, N. 2011. Ancestral consciousness among the Zulu - a Wilberian perspective. Journal of Psychology in Africa, 21(1), 131-138.

Epstein, M. 1996. Thoughts without a thinker. London, UK: Duckworth.

Fonda, M. 1995. The polycentric self as suggested by the object relations theory of Klein, Fairburn and Winnicott. Accessed on 12-52013 from http://www.religiousworlds.com/fondarosa/polypap.html

James, W. 1890. Principles of psychology. New York, NY: Henry Holt.

Jobling, M.A., Hurles, M.E. \& Tyler-Smith, C. 2004. Human evolutionary genetics. New York: Garland Publishing.

Jung, C. G. 1995. Memories, dreams, reflections. London, England: Fontana.

Leahey, T. H. 1987. A history of psychology: main currents in psychological thought. Englewood Cliffs, NJ: Prentice Hall.

Loubser, 2004. Unpacking the expression 'indigenous knowledge systems". Indilinga. African Journal of Indigenous Knowledge Systems, 4(1), 74-88.

Merton, T. 2006. 'New seeds of contemplation' (pages 545-552) in McGinn, B. 2006. The essential writings of Christian mysticism. New York, NY: Random House,

Moustakas, C. E. 1994. Phenomenological research methods. Thousand Oaks, CA: Sage.

Myers, L. 1993. Understanding an Afrocentric world view: introduction to an optimal psychology. Kendal Hunt: Dubuque.

Reid, D. 1998. Chi-Gung. Harnessing the power of the universe. London, UK: Simon and Schuster.

Sherwood, P.M. 2012. Holistic Counselling: Through the Shadow to Compassion. Bunbary, Western Australia: Sophia Publications.

Steiner, R. 1999. A psychology of body, mind and spirit. New York, NY: Rudolf Steiner Press.

Terre Blanche, M., Durrheim, K., \& Painter, D. 2006. Research in practice; applied methods for the social sciences. Cape Town, WC: University of Cape Town Press. 
Investigation into contemplating the self in a spiritual and transpersonal psychological context.

Versveldt, M. 2010. Our selves. Pretoria, RSA: Pretoria Book House.

Visser, F. 2003. Ken Wilber: Thought as passion. Albany NY: State University of New York.

Wilber, K. 1982. Odyssey: a personal inquiry into humanistic and transpersonal psychology. Journal of Humanistic Psychology, 22(1), 57-90.

Wilber, K, 1996. The Atman project: A transpersonal view of human development. Wheaten, IL: Quest.

Wilber, K. 1997. An integral theory of consciousness. Journal of Consciousness Studies, 4(1), 71-92.

Wilber, K. 2000. Integral psychology. Boston, MA: Shambhala.

Wilber, K. 2001. Eye to eye. Boston, MA: Shambhala.

Wilber, K. 2007. Integral spirituality. Boston, MA: Integral Books.

Wilber, K., Engler, J., \& Brown, D. P. 1986. Transformations of consciousness: conventional and contemplative perspectives on development. Boston, MA: Shambhala.

\section{Acknowledgment}

This work is based on research supported by the University of Zululand and the South African National Research Foundation (NRF). Any opinion, finding and conclusion or recommendation expressed in this material is that of the author(s) and the NRF does not accept any liability in regard thereto. 